Pesq. Vet. Bras. 31(2):158-164, fevereiro 2011

\title{
Hepatite infecciosa canina em cães naturalmente infectados: achados patológicos e diagnóstico imuno-histoquímico'
}

INDEX TERMS: Hepatitis, dogs, necrosis, hemorrhage, immunohistochemistry.

RESUMO.- Vinte e três cães com hepatite infecciosa canina $(\mathrm{HIC})$ foram analisados com base nos seus dados gerais, achados clínicos, patológicos e imuno-histoquímicos. As principais lesões macroscópicas encontradas foram palidez do fígado (17/23), hepatomegalia (10/23) e hemorragia (21/23). Observou-se também edema da parede da vesícula biliar (11/23), malhas de fibrina cobrindo a superfície capsular hepática (8/23) e icterícia (6/23). Acentuada necrose hepatocelular foi encontrada associada à identificação de corpúsculos intranucleares anfofílicos e basofílicos em hepatócitos e células endoteliais (22/23) característicos de adenovírus. Identificou-se no baço e linfonodos necrose linfoide, hemorragia e menor ocorrência de corpúsculos intranucleares em células reticuloendoteliais. A imuno-histoquímica (IHQ) foi positiva para adenovírus canino tipo 1 em

\footnotetext{
${ }^{1}$ Recebido em 15 de junho de 2010.

Aceito para publicação em 15 de outubro de 2010.

Parte da tese de Doutorado do primeiro autor.

2 Setor de Patologia Veterinária, Faculdade de Veterinária, Universidade Federal do Rio Grande do Sul, Avenida Bento Gonçalves 9090, Bairro Agronomia, Porto Alegre, RS 91540-000, Brasil. *Autor para correspondência:_davetpat@ufrgs.br
}

todos os animais analisados. Os principais órgãos positivos na IHQ foram fígado (23/23), telencéfalo (22/22), cerebelo $(16 / 20)$ e rim (16/21). Maior marcação de antígenos viral foi observada em hepatócitos e no endotélio vascular do encéfalo e dos tufos glomerulares renais.

TERMOS DE INDEXAÇÃO: Hepatite, cães, necrose, hemorragia, imuno-histoquímica.

\section{INTRODUÇÃO}

A hepatite infecciosa canina (HIC) é uma doença viral sistêmica causada pelo adenovírus canino tipo 1 (CAV-1) (Decaro et al. 2008) e acomete principalmente cães jovens e não vacinados (Timoney et al. 1988). Como importante característica, o CAV-1 possui tropismo por hepatócitos e células endoteliais (Zee \& MacLachlan 2004), resultando em grave quadro clínico devido à necrose hepatocelular e hemorragia sistêmica (Greene 2006, Decaro et al. 2008).

A HIC foi diagnosticada primeiramente em cães em 1930 (Decaro et al. 2008) e com o decorrer dos anos se tornou uma doença comum e amplamente diagnosticada em diferentes países (Carvalho et al. 1975). Com a utilização de 
vacinas para a prevenção da doença, a ocorrência de HIC apresenta-se reduzida pelo mundo e atualmente é mais descrita em países sem adequados programas de vacinação ou que não apresentam um controle de importação de animais (Decaro et al. 2007, 2008).

O objetivo deste trabalho é descrever as características gerais, os achados clinicopatológicos e o diagnóstico por imuno-histoquímica (IHQ) de 23 casos de HIC diagnosticados no Setor de Patologia Veterinária da Universidade Federal do Rio Grande do Sul (SPV-UFRGS) entre 1996 e 2009.

\section{MATERIAL E MÉTODOS}

Registros de necropsias realizadas em cães no SPV-UFRGS foram revisados do período de janeiro de 1996 a dezembro de 2009 para identificar cães diagnosticados com HIC. Todos os diagnósticos foram baseados em achados histológicos de HIC. Dados gerais, históricos e achados patológicos dos cães com HIC foram registrados e analisados. Informações referentes ao sexo, raça, idade, ano da realização da necropsia, sinais clínicos, suspeita clínica e estado vacinal dos cães foram buscadas. Como diagnóstico complementar, realizou-se a identificação de antígeno viral pela técnica de IHQ em cortes histológicos de fígado, rim, pulmão, baço, linfonodo mesentérico, timo, telencéfalo e cerebelo. A técnica foi realizada pelo método estreptavidina-biotina ligada à peroxidase. Inibição da peroxidase foi realizada com peróxido de hidrogênio a $10 \%$ em solução de metanol durante 30 minutos. A recuperação antigênica ocorreu com a utilização de proteinase K ready-to-use (S3020, DakoCytomation) por 1 minuto. O bloqueio das reações inespecíficas foi realizado com leite em pó por 20 minutos. Para diagnóstico de HIC, utilizou-se anticorpo monoclonal para adenovírus canino tipo 1 (VMRD - 2E10-H2) na diluição de 1:400 durante o período de 14-16 horas (overnight) a $4^{\circ} \mathrm{C}$. Após esta fase, os cortes histológicos foram incubados com anticorpo secundário biotinilado ligado a estreptavidina-peroxidase (kit LSAB-K0690, DakoCytomation) durante um período total de 40 minutos. Como cromógeno utilizou-se o 3,3'diaminobenzidina (DAB-K3468, DakoCytomation) durante um minuto.

\section{RESULTADOS}

Durante o período de janeiro de 1996 a dezembro de 2009 realizaram-se 23 diagnósticos de HIC, de um total de 6.993 necropsias em cães realizadas no SPV-UFRGS, representando $0,34 \%$ das necropsias de cães. Foram afetados 13 fêmeas e 10 machos. A idade foi informada em 21 casos,

Quadro 1. Distribuição dos casos de hepatite infecciosa canina diagnosticados com o ano da realização da necropsia, dados gerais e informações clínicas dos 23 cães

\begin{tabular}{|c|c|c|c|c|c|c|c|}
\hline Caso & $\begin{array}{c}\text { Ano da } \\
\text { necropsia }\end{array}$ & Raça & Sexo & Idade & Vacinação & $\begin{array}{l}\text { Suspeita } \\
\text { clínica }\end{array}$ & Histórico e sinais clínicos \\
\hline 1 & 1998 & SRD & Fêmea & 12 meses & NV & NR & NR \\
\hline 2 & 2003 & SRD & Fêmea & 36 meses & NR & NR & Edema subcutâneo e anorexia. \\
\hline 3 & 2005 & Chow Chow & Fêmea & 2 meses & NR & Intoxicação & $\begin{array}{l}\text { Quadro clínico de um dia com apa- } \\
\text { tia, vômitos, hipertemia e convulsões. }\end{array}$ \\
\hline 4 & 2005 & Pit Bull & Macho & NR & NR & NR & NR \\
\hline 5 & 2005 & SRD & Fêmea & 4 meses & NV & $\begin{array}{l}\text { Babesiose ou } \\
\text { leptospirose }\end{array}$ & Apatia e anorexia. \\
\hline 6 & 2005 & Boxer & Fêmea & 45 dias & NV & Parvovirose & $\begin{array}{l}\text { Quadro clínico de dois dias com vô- } \\
\text { mitos e mucosas pálidas. }\end{array}$ \\
\hline 7 & 2006 & SRD & Fêmea & NR & NR & $\begin{array}{l}\text { HIC ou } \\
\text { leptospirose }\end{array}$ & $\begin{array}{l}\text { Quadro clínico de poucas horas com } \\
\text { icterícia e fezes com sangue. }\end{array}$ \\
\hline 8 & 2006 & SRD & Fêmea & 4 meses & 3 doses & $\begin{array}{l}\text { Babesiose ou } \\
\text { cinomose }\end{array}$ & $\begin{array}{l}\text { Quadro clínico de } 3 \text { dias com icterícia, } \\
\text { anorexia e dificuldade de locomoção. }\end{array}$ \\
\hline 9 & 2006 & Poodle & Fêmea & 2 meses & 1 dose & NR & $\begin{array}{l}\text { Quadro clínico de poucas horas com } \\
\text { apatia e anorexia. }\end{array}$ \\
\hline 10 & 2006 & Labrador & Macho & 3 meses & NV & Verminose & Apatia, convulsões e mucosas pálidas. \\
\hline 11 & 2008 & SRD & Fêmea & 5 meses & 3 doses & NR & Apatia e diarreia. \\
\hline 12 & 2008 & SRD & Macho & 2 meses & NV & Intoxicação & $\begin{array}{l}\text { Encontrado morto, sem sinais clínicos } \\
\text { anteriores. }\end{array}$ \\
\hline 13 & 2008 & SRD & Macho & 3 meses & NV & NR & Apatia, anorexia e icterícia. \\
\hline 14 & 2008 & SRD & Macho & 2 meses & NV & Parvovirose & $\begin{array}{l}\text { Apatia, hipotermia, diarreia e mucosas } \\
\text { pálidas. }\end{array}$ \\
\hline 15 & 2009 & Yorkshire & Macho & 2 meses & NV & Parvovirose & Fezes pastosas e com sangue. \\
\hline 16 & 2009 & $\begin{array}{l}\text { Pastor } \\
\text { Alemão }\end{array}$ & Fêmea & 4 meses & 2 doses & Parvovirose & Anorexia e diarreia. \\
\hline 17 & 2009 & Shih Tzu & Macho & 2 meses & 1 dose & NR & Anorexia, apatia e morte em 2 dias. \\
\hline 18 & 2009 & SRD & Macho & 1 mês & NR & Leptospirose & Apatia, icterícia e petéquias na pele. \\
\hline 19 & 2009 & Poodle & Fêmea & 2 meses & NR & NR & NR \\
\hline 20 & 2009 & SRD & Fêmea & 3 meses & NV & Leptospirose & Apatia, icterícia e dispneia. \\
\hline 21 & 2009 & SRD & Macho & 2 meses & NR & NR & NR \\
\hline 22 & 2009 & $\begin{array}{l}\text { Pastor } \\
\text { Alemão }\end{array}$ & Fêmea & 3 meses & NR & Parvovirose & $\begin{array}{l}\text { Apatia, anorexia, mucosas pálidas e di- } \\
\text { arreia com sangue. }\end{array}$ \\
\hline 23 & 2009 & Yorkshire & Macho & 36 meses & NR & Intoxicação & $\begin{array}{l}\text { Quadro clínico de um dia e com con- } \\
\text { vulsões. }\end{array}$ \\
\hline
\end{tabular}

SRD = Sem raça definida, NV = não vacinado, NR = não relatado, $\mathrm{HIC}=$ hepatite infecciosa canina. 
obtendo-se uma média de idade de seis meses, variando de 45 dias a três anos. Animais sem raça definida representaram $52,2 \%$ dos casos e cães com raça $47,8 \%$ das necropsias. Em 14 casos, informações quanto ao programa de vacinação foram relatadas pelo médico veterinário ou proprietário. Desses, nove cães não receberam nenhuma dose de vacina polivalente canina (apresenta antígeno vacinal de adenovírus), dois cães receberam três doses desse tipo de vacina, dois filhotes receberam uma dose e um cão recebeu duas doses. A suspeita clínica, informada pelo veterinário ou proprietário, foi relatada em 15 casos. As duas
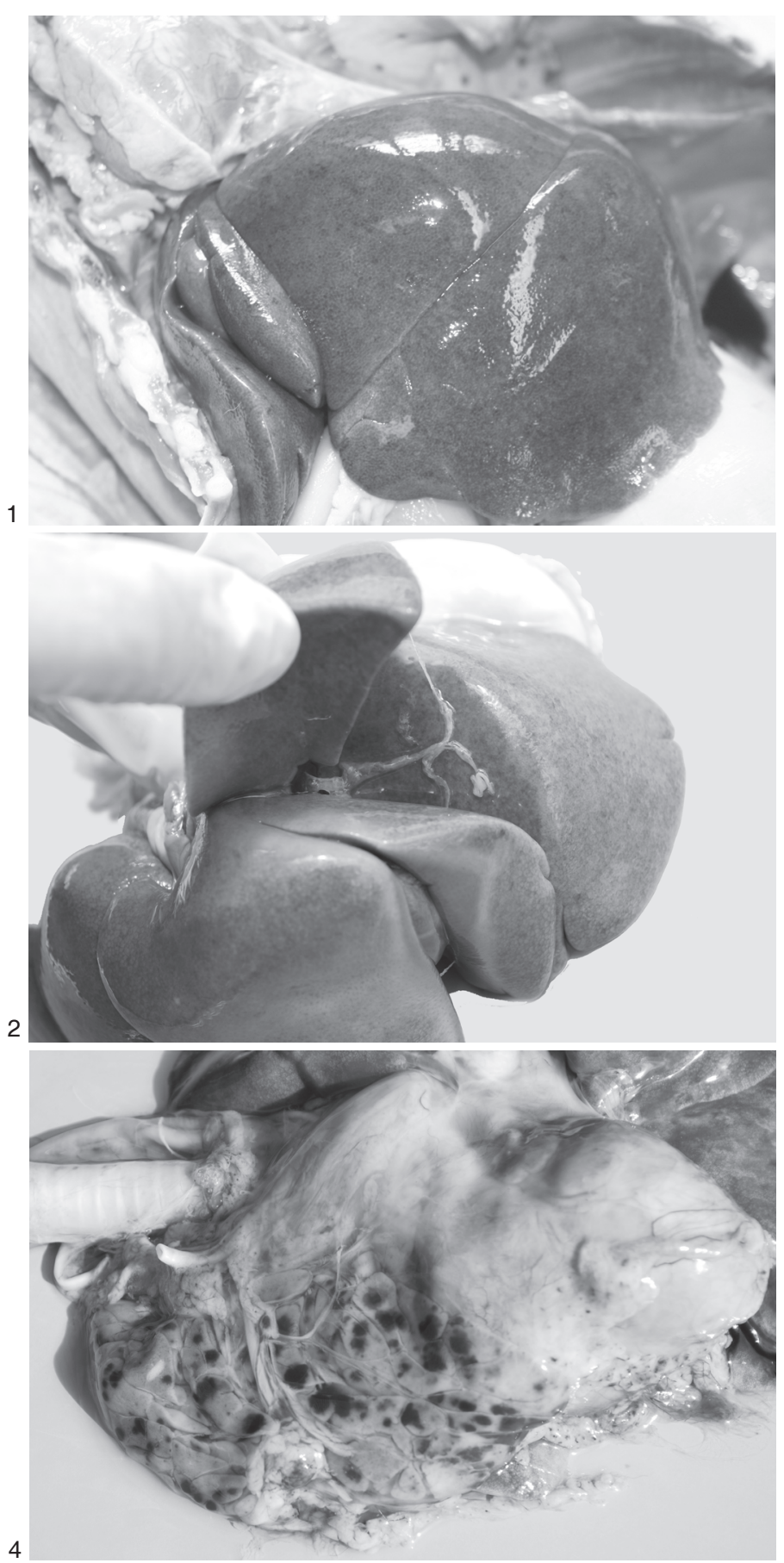

principais suspeitas clínicas relatadas foram parvovirose canina (4/15) e leptospirose (4/15), e em somente um caso foi cogitada a possibilidade de HIC. Em 19 cães, informações do histórico clínico foram dadas na requisição de necropsia. Os principais sinais clínicos relatados no histórico foram apatia (11/19), anorexia (8/19), icterícia (5/19) e diarreia (4/19). Dados gerais do cão, o ano da realização da necropsia e informações clínicas estão descritas no Quadro 1.

\section{Achados macroscópicos}

O exame de necropsia identificou alterações macroscópicas hepáticas em todos os cães (Quadro 1), caracterizadas principalmente por palidez (17/23) e friabilidade (13/23), hepatomegalia (10/23), focos de hemorragia (5/ 23) e acentuação do padrão lobular (5/23) (Fig.1). Observou-se discreto material fibrinoso na superfície capsular

Fig.1. Fígado de um cão com hepatite infecciosa canina, apresentando padrão lobular evidente e hemorragias na superfície capsular.

Fig.2. Fígado pálido e com fibrina na superfície capsular de um cão com hepatite infecciosa canina.

Fig.3. Vesícula biliar com edema acentuado em um cão com hepatite infecciosa canina.

Fig.4. Hemorragia tímica acentuada em um cão com hepatite infecciosa canina.

Fig.5. Hemoperitônio em um cão com hepatite infecciosa canina.
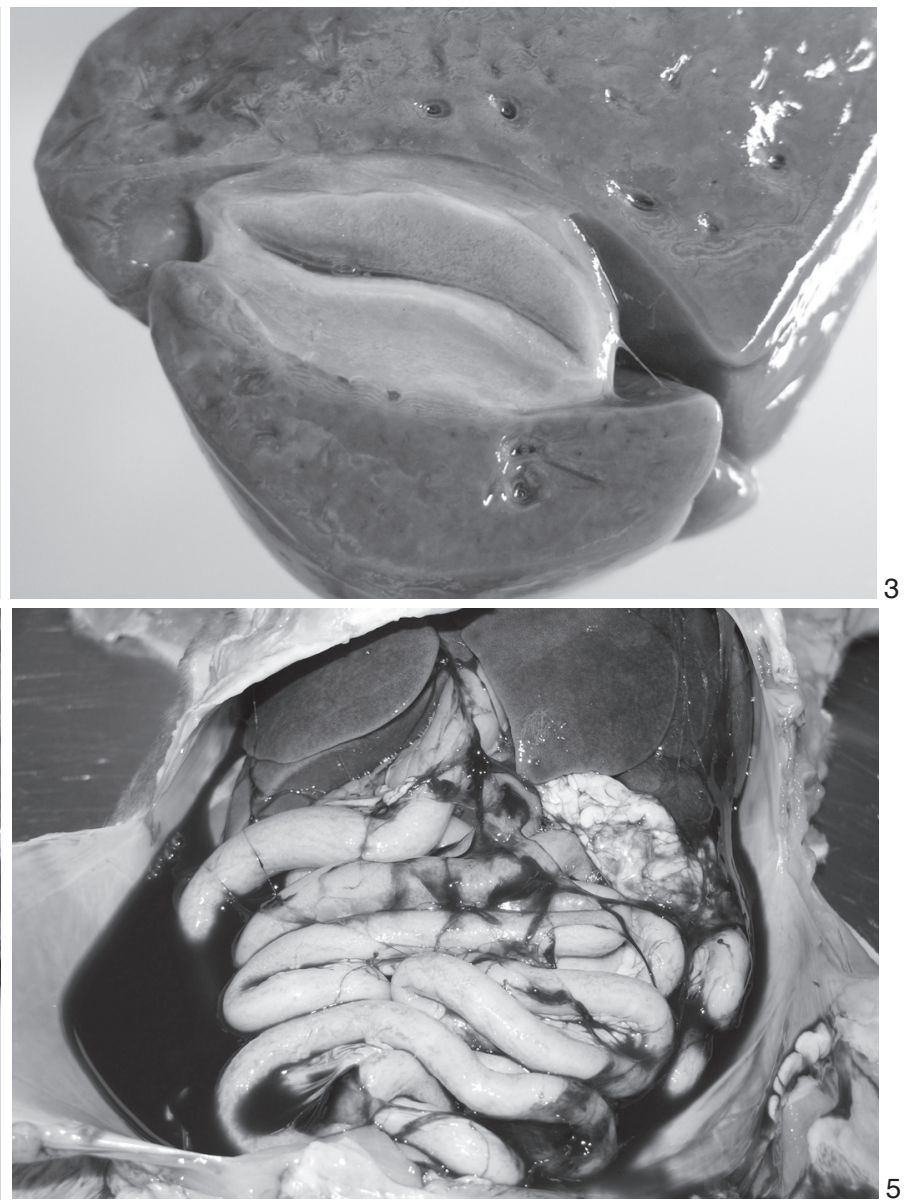
hepática e entre os lóbulos (8/23) (Fig.2) e edema da parede da vesícula biliar (11/23) (Fig.3). Fezes amolecidas foram vistas em dez animais e nesses casos se apresentava hemorrágica em sete. Icterícia foi observada em parte das necropsias (6/23). Grande parte dos casos (21/23) cursou com hemorragia em diferentes órgãos. O principal órgão acometido por essa alteração foi o intestino delgado (10/23), que apresentou hemorragia na luz e em alguns casos petéquias e equimoses na serosa e/ou mucosa. Observaram-se hemorragias também na mucosa e/ou serosa do estômago (6/23), timo (6/23) (Fig.4), pulmões (5/ 23), peritônio (4/23) (Fig.5), pele (4/23), fígado (3/23), coração (3/23), encéfalo (3/23), subcutâneo (1/23), mesentério $(1 / 23)$ e na serosa do cólon (1/23). Identificou-se serosa intestinal rugosa em nove das 23 necropsias, além de hiperemia da serosa e mucosa $(5 / 23)$ e placas de Peyer evidentes (4/23). No exame macroscópico de órgãos linfoides abdominais, observaram-se esplenomegalia (15/ 23) e aumento de linfonodos mesentéricos (14/23). Havia também edema tímico (4/23) (Fig.4), pulmonar (3/23), hidrotórax (2/23), ascite (2/23) e subcutâneo (2/23).

\section{Achados microscópicos}

A avaliação histológica apresentou variação no número de órgãos analisados. A descrição das lesões é seguida pela análise numérica, seguindo a regra (número de casos com a lesão/número de cortes histológicos analisados). No fígado encontrou-se necrose hepatocelular acentuada (23/23), com padrão centrolobular (14/23), massivo (5/23) e aleatório (4/23) (Fig.6). Outros achados no fígado incluíam congestão (13/23), hemorragia (10/23), leve infiltrado inflamatório formado por macrófagos e linfócitos ou misto (9/23), leve colestase (5/23) e vasculite linfoplasmocitária (3/23). As lesões microscópicas hepáticas identificadas em cada caso de HIC estão apresentadas no Quadro 2. Na vesícula biliar, somente foi observado edema na submucosa (8/13) associado à dilatação de vasos e autólise em grau variado.

Cortes histológicos de linfonodos mesentéricos revelaram necrose acentuada de células foliculares e interfoliculares (14/19), infiltrado de histiócitos (15/19), hemorragia (9/ $19)$, eritrofagocitose (8/19), rarefação linfoide (6/19) e hiperplasia linfoide (3/19). No baço identificou-se hemorragia (10/ $21)$, necrose linfoide (9/21), rarefação linfoide (8/21), infiltrado de histiócitos (6/21) e eritrofagocitose (3/21). No timo havia congestão acentuada (8/18), necrose linfoide (5/18), focos de hemorragia (6/18), rarefação linfoide moderada (4/18), edema interlobular (4/14) e hiperplasia linfoide da região cortical (3/14). Na avaliação pulmonar, identificou-se congestão (9/22), infiltrado inflamatório alveolar formado por linfócitos, macrófagos, plasmócitos ou misto (8/22), focos de hemorragia (6/22) e edema alveolar de grau variado (7/22). A histologia renal revelou congestão (8/21), degeneração tubular (5/21), glomerulonefrite membranosa discreta (4/21) e focos de hemorragia (3/21). No intestino delgado, observou-se necrose e rarefação linfoide nas placas de Peyer (7/ 19) e discreto infiltrado de linfócitos na mucosa (4/19). No encéfalo, havia congestão de vasos superficiais do córtex (8/22), vacuolização discreta multifocal da substância branca (6/22), raros focos de vasculite linfocitária (6/22), hemor-

Quadro 2. Identificação de edema da vesícula biliar, alterações macroscópicas e histológicas do fígado dos 23 cães com hepatite infecciosa canina

\begin{tabular}{|c|c|c|c|c|c|c|c|c|c|}
\hline \multirow[t]{2}{*}{ Caso } & \multirow{2}{*}{$\begin{array}{c}\text { Edema de } \\
\text { vesícula }\end{array}$} & \multirow[t]{2}{*}{ Macroscopia do fígado } & \multicolumn{7}{|c|}{ Microscopia fígado } \\
\hline & & & $\mathrm{NE}$ & $\mathrm{Cl}$ & $\mathrm{CO}$ & HE & $\mathrm{CL}$ & VA & $\mathrm{HT}$ \\
\hline 1 & + & Aumentado, pálido e friável. & + & + & + & + & - & - & - \\
\hline 2 & - & Friável, fibrina e manchas brancas. & + & + & + & + & - & - & - \\
\hline 3 & - & Pálido e friável. & + & + & + & - & + & + & + \\
\hline 4 & - & Pálido. & + & + & + & - & - & - & - \\
\hline 5 & - & Aumentado, pálido, padrão lobular evidente e com áreas vermelhas. & + & + & - & + & - & - & + \\
\hline 6 & - & Pálido, friável, fibrina e com padrão lobular evidente. & + & + & + & + & - & - & - \\
\hline 7 & + & Aumentado, pálido, friável e com padrão lobular evidente. & + & + & - & + & + & - & + \\
\hline 8 & - & Pálido e friável. & + & + & + & - & + & + & + \\
\hline 9 & + & Aumentado, pálido, friável e com pontos brancos. & + & + & + & + & - & - & - \\
\hline 10 & + & Aumentado, pálido, friável e com padrão lobular evidente. & + & + & + & + & - & - & - \\
\hline 11 & - & Pálido. & + & + & + & - & - & - & + \\
\hline 12 & + & Aumentado, pálido, friável e com fibrina. & + & + & + & + & + & - & + \\
\hline 13 & - & Pálido e friável. & + & + & - & - & + & + & + \\
\hline 14 & + & Aumentado, pálido, friável e com fibrina. & + & + & - & - & - & - & - \\
\hline 15 & + & Aumentado, pálido, friável e com fibrina. & + & + & - & - & + & - & + \\
\hline 16 & + & Aumentado & + & + & + & - & - & - & - \\
\hline 17 & - & Aumentado, pálido, friável e com padrão lobular evidente. & + & + & - & - & + & - & - \\
\hline 18 & - & Friável. & + & + & - & + & - & - & - \\
\hline 19 & + & Aumentado, pálido, friável. & + & + & + & + & + & - & - \\
\hline 20 & - & Friável. & + & + & - & - & - & - & - \\
\hline 21 & + & Aumentado. & + & + & - & - & - & - & - \\
\hline 22 & - & Aumentado, pálido, friável. & + & + & + & - & + & - & + \\
\hline 23 & + & Padrão lobular evidente. & + & - & - & + & + & - & + \\
\hline
\end{tabular}

$\mathrm{NE}=$ Necrose, $\mathrm{Cl}=$ corpúsculo de inclusão intranuclear, $\mathrm{CO}=$ congestão, $\mathrm{HE}=$ hemorragia, $\mathrm{CL}=$ colestase, $\mathrm{VA}=$ vasculite, $\mathrm{HT}=$ hepatite, $(+)$ = presente, $(-)=$ ausente. 

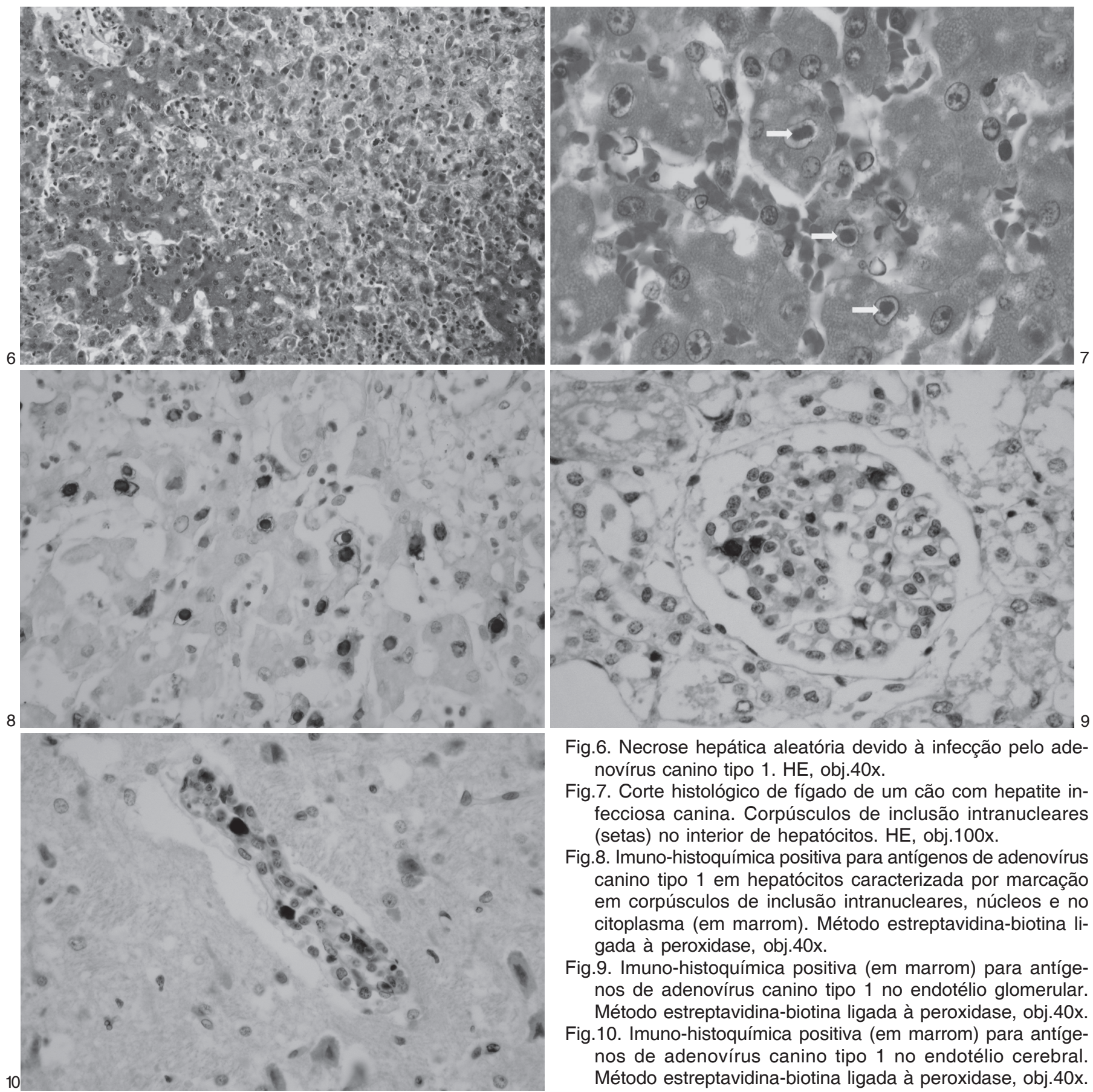

Fig.6. Necrose hepática aleatória devido à infecção pelo adenovírus canino tipo 1. HE, obj.40x.

Fig.7. Corte histológico de fígado de um cão com hepatite infecciosa canina. Corpúsculos de inclusão intranucleares (setas) no interior de hepatócitos. HE, obj.100x.

Fig.8. Imuno-histoquímica positiva para antígenos de adenovírus canino tipo $1 \mathrm{em}$ hepatócitos caracterizada por marcação em corpúsculos de inclusão intranucleares, núcleos e no citoplasma (em marrom). Método estreptavidina-biotina ligada à peroxidase, obj.40x.

Fig.9. Imuno-histoquímica positiva (em marrom) para antígenos de adenovírus canino tipo 1 no endotélio glomerular. Método estreptavidina-biotina ligada à peroxidase, obj.40x.

Fig.10. Imuno-histoquímica positiva (em marrom) para antígenos de adenovírus canino tipo 1 no endotélio cerebral. Método estreptavidina-biotina ligada à peroxidase, obj.40x.

ragia multifocal de grau variado (5/22) e necrose focal do neurópilo em área adjacente a hemorragia (2/22).

Corpúsculos intranucleares anfofílicos (Fig.7) característicos de adenovírus foram identificados em grande parte dos casos (22/23). O fígado foi o principal órgão na identificação de corpúsculos, apresentando-se grande número (12/ $23)$, pequeno número (8/23), moderado número (2/23) ou nenhum corpúsculo em um caso. Os corpúsculos de inclusão intranucleares foram encontrados principalmente em hepatócitos e em menor grau nas células de Kupffer e no endotélio vascular (em poucos casos ocorrendo no endotélio

glomerular renal, encefálico e tímico). Identificou-se reduzido número de corpúsculos intranucleares em células reticuloendoteliais do baço e de linfonodos mesentéricos.

\section{Exame imuno-histoquímico}

O resultado da IHQ foi positivo para adenovírus canino tipo $1 \mathrm{em}$ todos os cães. Entre os órgãos testados, os melhores resultados foram obtidos no fígado (23/23), telencéfalo (22/22), cerebelo (16/20) e rim (16/21) (Quadro $3)$. No fígado, antígeno viral foi identificado em maior número em hepatócitos, com marcação no citoplasma, nú- 
Quadro 3. Resultados dos testes imuno-histoquímicos em diferentes órgãos nos 23 cães com hepatite infecciosa canina

\begin{tabular}{|c|c|c|c|c|c|c|c|c|}
\hline Caso & Fígado & Rim & Baço & Linfonodo & Timo & Pulmão & Cérebro & Cerebelo \\
\hline 1 & $+++^{\mathrm{a}}$ & +++ & NA & NA & NA & - & +++ & NA \\
\hline 2 & + & + & + & NA & NA & NA & + & + \\
\hline 3 & + & + & - & NA & NA & - & ++ & ++ \\
\hline 4 & +++ & NA & ++ & - & - & - & + & + \\
\hline 5 & ++ & + & + & - & - & - & + & + \\
\hline 6 & + & + & - & ++ & - & - & ++ & - \\
\hline 7 & ++ & ++ & - & - & - & - & NA & NA \\
\hline 8 & +++ & +++ & NA & - & - & - & + & NA \\
\hline 9 & + & - & - & + & - & + & + & - \\
\hline 10 & +++ & +++ & - & NA & + & - & +++ & +++ \\
\hline 11 & ++ & - & + & - & NA & - & + & + \\
\hline 12 & +++ & ++ & ++ & ++ & + & - & ++ & +++ \\
\hline 13 & ++ & +++ & - & - & - & + & + & + \\
\hline 14 & +++ & + & - & - & ++ & - & + & - \\
\hline 15 & +++ & - & +++ & + & - & - & ++ & - \\
\hline 16 & +++ & +++ & - & - & + & + & ++ & ++ \\
\hline 17 & + & + & - & - & - & - & + & + \\
\hline 18 & +++ & +++ & ++ & + & + & + & +++ & + \\
\hline 19 & +++ & - & + & - & ++ & - & ++ & + \\
\hline 20 & + & NA & - & + & NA & - & + & + \\
\hline 21 & + & - & - & - & - & - & +++ & ++ \\
\hline 22 & +++ & +++ & +++ & + & +++ & +++ & +++ & ++ \\
\hline 23 & ++ & + & ++ & - & + & + & + & + \\
\hline
\end{tabular}

cleo e em corpúsculos de inclusão intranucleares (Fig.8). Porém, alguns corpúsculos de inclusão intranucleares não se apresentavam marcados. Observaram-se também marcação em células de Kupffer e ocasionalmente no endotélio vascular. No diagnóstico do animal que não apresentava corpúsculos de inclusão intranucleares no corte histológico de fígado, identificou-se hepatócitos marcados positivamente para CAV-1. No rim, marcação foi obtida unicamente em células endoteliais dos tufos glomerulares (Fig.9). No encéfalo, antígeno de CAV-1 foi identificado no endotélio vascular, com forte marcação do citoplasma, núcleo e corpúsculos de inclusão intranucleares (Fig.10). Em órgãos linfoides, observou-se menor número de cortes histológicos positivos para CAV-1 e baixa quantidade de linfócitos ou células endoteliais marcadas positivamente.

\section{DISCUSSÃO}

Durante o período de análise, os óbitos devido à hepatite infecciosa canina $(\mathrm{HIC})$ representaram reduzido número nas necropsias do SPV-UFRGS. Resultado semelhante foi identificado por Inkelmann et al. (2007), que encontrou HIC em 1,2\% dos diagnósticos numa avaliação de 5.361 necropsias de cães na região central do Rio Grande do Sul. Entretanto, os casos apresentados, relacionados com o aumento do número de casos, principalmente nos últimos dois anos (39,1\% dos casos analisados), podem estar associados a um deficiente programa de vacinação. $\mathrm{Na}$ avaliação vacinal dos cães, observou-se a doença em animais vacinados, mesmo tendo as três doses recomendadas. Esse resultado pode estar relacionado a uma menor qualidade da vacina aplicada ou a um deficiente estado imunológico dos animais. Fatores como inadequada conservação da vacina, modo de aplicação, intervalos entre as aplicações e estresse do animal podem ter contribuído para a ocorrência da infecção (Greene \& Schultz 2006).

A idade jovem encontrada na maior parte dos cães também é apresentada em outras publicações, indicando uma maior sensibilidade de jovens em adquirir HIC (Studdert \& Studdert 1972, Decaro et al. 2007, Inkelmann et al. 2007). Entretanto, o acometimento de caninos maiores de um ano também é descrita, podendo ocorrer pela não vacinação ou por um estado imunológico menos eficiente (Greene 2006, Inkelmann et al. 2007).

A suspeita clínica de HIC somente estava presente no histórico de um cão. Esse resultado pode estar relacionado à dificuldade de realizar um diagnóstico clínico de HIC, provavelmente devida ao curso agudo da doença, ou ao fato de que a HIC pode apresentar sinais clínicos inespecíficos ou alterações que são observadas em outras doenças de maior casuística. Dessa forma, os sinais apresentados em um caso de HIC podem apresentar semelhanças a casos de parvovirose canina. Além disso, juntamente a alterações hepáticas agudas observadas na HIC, alguns achados macroscópicos de HIC também são encontrados em casos de parvovirose canina, como fezes mais líquidas e hemorrágicas, serosa intestinal rugosa e alterações linfoides (Gelberg 2007). Com isso, durante a necropsia, os achados comumente apresentados por essas doenças confirmam um quadro clínico e patológico semeIhante e que somente será confirmado por meio de análise histológica e/ou por diagnóstico complementar.

A avaliação do padrão de necrose hepática revelou um predomínio de necrose centrolobular, padrão descrito em infecções por CAV-1 (Stalker \& Hayes 2007, Decaro et al. 
2008), porém outros padrões de necrose hepática, como aleatória, foram identificados. Esses achados também foram descritos por Inkelmann et al. (2007). Hemorragias em diferentes locais anatômicos se apresentaram comumente durante a necropsia. Essa alteração é ocasionada pelo desenvolvimento de coagulação intravascular disseminada (CID) provocada pela trombocitopenia, pelo aumento no tempo de protrombina e diminuição dos fatores de coagulação (Greene 2006, Decaro et al. 2008). Essas anormalidades são desencadeadas pela lesão do CAV-1 no endotélio, com ativação da coagulação pela exposição de substâncias pró-coagulantes no subendotélio, provocando uma coagulopatia de consumo com a utilização de plaquetas e fatores de coagulação (Stalker \& Hayes 2007).

Outros achados patológicos como icterícia, edema de vesícula biliar e depósito de fibrina na superfície hepática podem ser identificados no exame de necropsia, auxiliando o diagnóstico de HIC. Porém, a ocorrência destas lesões é menor (Greene 2006, Inkelmann et al. 2007). O resultado apresentado na vesícula biliar difere de Cornwell \& Wright (1969), que em estudo experimental de HIC em filhotes, observaram edema de vesícula biliar em muitos cães. Algumas possibilidades são colocadas para a formação do edema, como aumento da pressão portal, diminuição da pressão osmótica ou combinação de ambos os fatores (Van Breda Vriesman et al. 2007).

O diagnóstico complementar pela IHQ foi eficaz na identificação do CAV-1 em cortes histológicos. Em um caso, auxiliou o diagnóstico de HIC na ausência de corpúsculos de inclusão intranucleares. A identificação de antígeno viral, principalmente em hepatócitos e no endotélio vascular, confirma o tropismo do CAV-1 por esses locais, ajudando no entendimento da patogenia da HIC. Marcação por IHQ não foi identificada em todos os corpúsculos de inclusão intranucleares que caracterizam a infecção pelo CAV-1, resultado também observado em outros trabalhos de HIC que utilizaram a IHQ como ferramenta de diagnóstico (Rakich et al. 1986, Crouinard et al. 1998, Inkelmann et al. 2008). Segundo Rakich et al. (1986), corpúsculos de inclusões são formados por uma matriz amorfa com variada quantidade de material viral, podendo conter estruturas virais antigenicamente diferentes e dessa forma podem não ligar ao anticorpo específico de CAV-1.

Alterações linfoides foram observadas em diferentes órgãos e associadas à identificação histológica do CAV-1 pela IHQ também demonstraram o tropismo viral por células linfoides. Esses resultados também foram descritos em outros estudos com a identificação de achados patológicos e a identificação viral em cortes histológicos (Cornwell \& Wright 1969, Inkelmann et al. 2007, 2008).
Agradecimentos.- Aos demais membros do Setor de Patologia Veterinária da UFRGS pelo auxílio técnico. Ao Conselho Nacional de Desenvolvimento Científico e Tecnológico (CNPq) pelo auxílio financeiro deste trabalho.

\section{REFERÊNCIAS}

Carvalho R.P.S., Soborg F. \& Souza V.A.U.F. 1975. Canine hepatitis virus infections in dogs of São Paulo city, Brazil. Arqs Inst. Biológico, São Paulo, 42:93-98.

Cornwell H.J.C. \& Wright N.G. 1969. The pathology of experimental infectious canine hepatitis in neonatal puppies. Res. Vet. Sci. 10:156160.

Crouinard L., Martineau D., Forget C. \& Girad C. 1998. Use of polymerase chain reaction and immunohistochemistry for detection of canine adenovirus type 1 in formalin-fixed, paraffin-embedded liver of dogs with chronic hepatitis or cirrhosis. J. Vet. Diagn. Invest. 10:320-325.

Decaro N., Campolo M., Elia G., Buonavoglia D., Colaianni M.L., Lorusso A., Mari V. \& Buonavoglia C. 2007. Infectious canine hepatitis: An "old" disease reemerging in Italy. Res. Vet. Sci. 83:269-273.

Decaro N., Martella V. \& Buonavoglia C. 2008. Canine adenoviruses and herpesvirus. Vet. Clin. Small Anim. 38:799-814.

Gelberg H.B. 2007. Alimentary system, p.378-380. In: McGavin M.D. \& Zachary J.F. (Eds), Pathologic Basis of Veterinary Disease. $4^{\text {th }}$ ed. Mosby Elsevier, St Louis. 1476p.

Greene C.E. 2006. Infectious canine hepatitis and canine acidophil cell hepatitis, p.41-53. In: Ibid. (Ed), Infectious Diseases of the Dog and Cat. $3^{\text {rd }}$ ed. Saunders Elsevier, St Louis. 1387p.

Greene C.E. \& Schultz R. D. 2006. Immunoprophylaxis, p.1069-1119. In: Greene C.E. (Ed), Infectious Diseases of the Dog and Cat. $3^{\text {rd }}$ ed. Saunders Elsevier, St Louis. 1387p.

Inkelmann M.A., Anjos B.L., Kommers G.D., Fighera R.A. \& Barros C.S.L. 2008. Aspectos imunoistoquímicos da hepatite infecciosa canina. Ciência Rural 38:2636-2640.

Inkelmann M.A., Rozza D.B., Fighera R.A., Kommers G.D., Graça D.L., Irigoyen L.F. \& Barros C.S.L. 2007. Hepatite infecciosa canina: 62 casos. Pesq. Vet. Bras. 27:325-332.

Rakich P.M., Prasse K.W. Lukert P.D. \& Cornelius L.M. 1986. Immunohistochemical detection of canine adenovirus in paraffin sections of liver. Vet. Pathol. 23:478-484.

Stalker M.J. \& Hayes M.A. 2007. Liver and biliary system. In: Maxie M.G. (Ed.), Jubb, Kennedy, and Palmer's Pathology of Domestic Animals, p.297-388. Vol.2. $5^{\text {th }}$ ed. Saunders Elsevier, Philadelphia.

Studdert M.J. \& Studdert V.P. 1972. Recovery of infectious canine hepatitis virus from dogs with different clinical syndromes. Aust. Vet. J. 48:554-557.

Timoney J.F., Gillespie J.H., Scott F.W. \& Barlough J.E. 1988. The adenoviridae, p.532-551. In: Ibid. (Eds), Hagan and Bruner's Microbiology and Infectious Diseases of Domestic Animals. $8^{\text {th }}$ ed. Cornell University Associates, New York. 951p.

Van Breda Vriesman A.C., Engelbrecht M.R., Smithuis R.H.M. \& Puylaert J.B.C.M. 2007. Diffuse gallbladder wall thickening: Differential diagnosis. Am. J. Roentgenol. 188:495-501.

Zee Y.C. \& MacLachlan N.J. 2004. Adenoviridade, p.317-319. In: Hirsh D.C., MachLachlan N.J. \& Walker R.L. (Eds), Veterinary Microbiology. $2^{\text {nd }}$ ed. Blackwell Publishing, lowa. 